\title{
Molecular Analysis of 23 Exons of the CFTR Gene in Brazilian Patients Leads to the Finding of Rare Cystic Fibrosis Mutations
}

GISELDA M. K. CABELLO,${ }^{1}$ PEDRO H. CABELLO,${ }^{1}$ KOKO OTSUKI, ${ }^{2}$ MARIA EMÍLIA GOMBAROVITS ${ }^{3}$ JUAN C. LLERENA JR., ${ }^{4}$ AND OCTAVIO FERNANDES ${ }^{3}$

\begin{abstract}
To define mutations present in 23 exons and flanking intronic sequences of the cystic fibrosis transmembrane conductance regulator (CFTR) gene in 95 patients from Rio de Janeiro, Brazil, we carried out single-strand conformation polymorphism analysis and automated direct sequencing. Mutation detection was achieved in $45 \%$ of the alleles presented, and complete genotyping (two mutated alleles) was accomplished in $34.7 \%$ of the patients. Twenty patients $(21.1 \%)$ were found to carry only one mutation, whereas mutated alleles could not be observed in 42 patients $(44.2 \%)$. Eleven mutations were found, of which four were characterized as rare mutations: P205S (1.05\%), Y1092X (0.53\%), S549R (0.53\%), and S4X (0.53\%). The DF508 mutation in this population sample showed a frequency of $28.42 \%$. The low number of individuals (10 of $95 ; 10.5 \%)$ with compound heterozygous (DF508/non-DF508) genotypes could indicate the presence of another severe mutation leading to the premature death of these individuals. In 4 of the aforementioned 10 individuals with compound heterozygous genotypes, the D-7-2-1-2 (XV2c-KM19-IVS6a-TUB9-M470-T854) haplotype was defined.
\end{abstract}

Cystic Fibrosis (CF), a worldwide disease occurring in most ethnic groups, is a generalized exocrine disorder characterized by highly variable clinical presentation. Both severity of disease and rate of progression of CF show extreme heterogeneity; some of these variations may result from the type of mutation on the cystic fibrosis transmembrane conductance regulator (CFTR) gene. Since isolation of the gene, which has 27 exons scattered over a region of 230 kilobase pairs (Kerem et al. 1989), more than 1,300 mutations and sequence variations have been reported to the Cystic Fibrosis Genetic Analysis Consortium (2004). The

\footnotetext{
${ }^{1}$ Laboratório de Genética Humana, Departamento de Genética, Instituto Oswaldo Cruz, FIOCRUZ, Av. Brasil 4365, Rio de Janeiro 21045-900, Brazil.

${ }^{2}$ Laboratório de Genética Molecular de Microrganismos, Departamento de Genética, Instituto Oswaldo Cruz, FIOCRUZ, Rio de Janeiro, Brazil.

${ }^{3}$ Departamento de Medicina Tropical, Instituto Oswaldo Cruz, FIOCRUZ, Rio de Janeiro, Brazil.

${ }^{4}$ Centro de Genética Médica, Instituto Fernandes Figueira, FIOCRUZ, Rio de Janeiro, Brazil.
}

Human Biology, February 2005, v. 77, no. 1, pp. 125-135.

Copyright (C) 2005 Wayne State University Press, Detroit, Michigan 48201-1309

KEY WORDS: CYSTIC FIBROSIS, CFTR GENE, SINGLE-STRAND CONFORMATION POLYMORPHISM (SSCP) ANALYSIS, BRAZILIAN POPULATION. 
incidence of the major CF mutation, a deletion of 3 base pairs in exon 10, named DF508, varies from 17.9\% (Messaoud et al. 1996) to 87\% (Schwartz et al. 1990; European Working Group on Cystic Fibrosis Genetics 1990) in the CF population, depending on the ethnic and geographic background. Most of the other nonDF508 CF mutations have marked variations in frequency in different geographic locations and ethnic groups. Therefore accurate knowledge of the CF mutations present in each population and their relative frequencies leads to a better understanding of the biological function of the CFTR protein and facilitates the development of more effective strategies for diagnosis, accurate risk assessments, and patient management.

In previous studies, molecular genetic analysis of Brazilian patients with $\mathrm{CF}$ in Rio de Janeiro was performed for eight Caucasian mutations. Initially these individuals were tested for 8 of the most common CFTR gene mutations on the basis of worldwide frequencies (Tsui 1992), and the DF508, G542X, and G551D mutations were detected. Later, the single-stranded conformation polymorphism (SSCP) approach was used to analyze the remaining undefined alleles, and the $3120+1 \mathrm{G} \rightarrow \mathrm{A}$ mutation was identified in this same population sample. Cabello et al. $(1999,2001)$ predicted that the incidence of CF is 1 in 6,902 births in the Rio de Janeiro population. Cabello's studies showed that DF508 presents a lower frequency in Rio de Janeiro $(\cong 30 \%)$ than in other Brazilian regions $(\cong 48 \%)$ (Raskin et al. 1993; Bernardino et al. 2000; Streit et al. 2003). These regional differences were mainly related to the proportion of the ethnic admixture and to the geographic diversity of the European ascendants.

Few studies regarding molecular analyses of the CFTR gene have been reported in Brazil, and the diversity of CFTR mutations corresponds to the great population heterogeneity present in the distinct Brazilian regions. These rare reports show that molecular analyses are important to define the regional mutation spectrum.

In the present study we aim to perform a complete characterization of $\mathrm{CF}$ mutations in Brazilian CF patients from Rio de Janeiro, using SSCP, restriction fragment length polymorphism (RFLP) analysis, and automatic sequencing.

\section{Materials and Methods}

Patients. Blood samples were collected from 95 unrelated CF patients and from their parents, when they were available. Consent forms were signed during the medical interview for all patients and relatives. The National Committee for Research on Human Subjects, a department of the Ministry of Health, approved the project. The criteria for CF diagnosis were based on typical clinical manifestations and high levels of sweat electrolytes.

Methods. Genomic DNA was isolated as previously reported (Miller et al. 1988). All patients were screened for nine common Caucasian CF mutations 
by distinct methodologies. DF508 was investigated using heteroduplex analysis (Rommens et al. 1990). R117H, 621 + 1G $\rightarrow$ T, G542X, G551D, R553X, and $\mathrm{N} 1303 \mathrm{~K}$ were searched by primer-mediated PCR restriction fragment analysis (Gasparini et al. 1992; Axton and Brock 1995). The presence of W1282X and $3120+1 \mathrm{G} \rightarrow \mathrm{A}$ were tested using naturally occurring restriction site analysis (Vidaud et al. 1990; Padoa et al. 1999).

After the first screening, patients who presented alleles that were still undefined in one or both CF chromosomes, were evaluated using nonradioactive SSCP analysis. Exons used for the SSCP analysis were amplified using a set of primers and conditions (shown in Table 1) in a $50 \mu \mathrm{L}$ reaction mixture, as described elsewhere (Cabello et al. 2001). Ten microliters of amplified products were mixed with an equal volume of formamide loading dye (95\% formamide, $10 \mathrm{mM} \mathrm{NaOH}$, $0.05 \%$ xylene cyanol, and $0.05 \%$ bromophenol blue), and the mixture was then boiled for 5-7 min and placed on ice before loading on SSCP minigels applied on a GenePhor system (Amersham Biosciences). Gels were run at $400 \mathrm{~V}$ for 2-3 $\mathrm{hr}$ at $6^{\circ} \mathrm{C}$, and the SSCP banding patterns were detected by silver staining.

The coding and flanking intronic sequences from 23 exons of the CFTR gene were analyzed. Each detected electrophoretic variant was sequenced using an automated DNA sequencer (ABI Prism 377, Applied Biosystems) to identify specific mutations. Novel mutations in CF patients were further investigated in the parents' DNA.

Gene frequencies were estimated using the maximum-likelihood method, and Hardy-Weinberg equilibrium was tested using the chi-square test. These analyses were performed with GENIOC statistical software (Cabello and Krieger 1977).

\section{Results}

The screening of the whole coding region and flanking intronic sequences from 23 exons of the CFTR gene in 190 chromosomes allowed us to identify 11 different mutations [DF508, G85E, $3120+1 \mathrm{G} \rightarrow \mathrm{A}$, R334W, G542X, P205S, G551D, R1162X, Y1092X (C > A), S549R (T > G), and S4X]. Six of these mutations were observed with a frequency higher than $1 \%$ (DF508, G85E, $3120+1 \mathrm{G} \rightarrow \mathrm{A}, \mathrm{R} 334 \mathrm{~W}, \mathrm{G} 542 \mathrm{X}$, and P205S).

The DF508 mutation, found in 54 of the 190 chromosomes, accounts for $28.42 \%$ of the CF alleles. It was observed in 13 homozygous patients, in 10 compound heterozygous individuals with an unknown mutation, and in 18 patients who were compound heterozygous with 9 identified mutations in this study [G85E, $3120+1 \mathrm{G} \rightarrow \mathrm{A}$, R334W, G542X, P205S, G551D, R1162X, Y1092X $(\mathrm{C}>\mathrm{A})$, and $\mathrm{S} 4 \mathrm{X}]$. Five of the aforementioned mutations present a frequency higher than 1\% (G85E, 3120 + 1G $\rightarrow$ A, R334W, G542X, and P205S).

The G85E mutation was found in $9(4.73 \%)$ of the 190 chromosomes, 2 of them in a single homozygous patient, 5 in patients who are compound heterozy- 
Table 1. Oligonucleotides and Conditions Used for PCR SSCP Analysis

\begin{tabular}{|c|c|c|c|c|c|}
\hline Exon & $\begin{array}{l}5^{\prime} \text { PCR } \\
\text { Primer }\end{array}$ & $\begin{array}{l}3^{\prime} \text { PCR } \\
\text { Primer }\end{array}$ & $\begin{array}{c}\text { Annealing } \\
\text { Temperature }\left({ }^{\circ} \mathrm{C}\right)\end{array}$ & $\begin{array}{c}\text { Extension Time } \\
(\text { Minutes })\end{array}$ & Reference \\
\hline 1 & $\alpha 1 \mathrm{R}$ & $10 \mathrm{D}$ & 63 & 0.8 & Shackleton et al. (1994) \\
\hline 2 & $2 \mathrm{bPF}$ & $2 \mathrm{bPR}$ & 60 & 2.5 & Shackleton et al. (1994) \\
\hline 3 & $3 i-5$ & $3 i-3$ & 60 & 1.5 & Zielenski et al. (1991) \\
\hline \multirow[t]{2}{*}{4} & $4 i-5$ & $4 \mathrm{~S} 3 \mathrm{~L}^{\mathrm{a}}$ & 62 & 0.8 & Zielenski et al. (1991) \\
\hline & $4 \mathrm{~S} 1 \mathrm{R}^{\mathrm{a}}$ & $4 i-3$ & 62 & 0.8 & Zielenski et al. (1991) \\
\hline 5 & $5 \mathrm{i}-5$ & $5 \mathrm{i}-3$ & 62 & 2.0 & Zielenski et al. (1991) \\
\hline $6 a$ & 6aii- $5^{\mathrm{a}}$ & 6aii- $3^{\mathrm{a}}$ & 58 & 0.8 & \\
\hline $6 b$ & $6 \mathrm{bii}-5^{\mathrm{a}}$ & $6 \mathrm{bi}-3$ & & & Zielenski et al. (1991) \\
\hline \multirow[t]{2}{*}{7} & $7 \mathrm{i}-5$ & $7 \mathrm{~S} 1 \mathrm{~L}^{\mathrm{a}}$ & 62 & 0.8 & Zielenski et al. (1991) \\
\hline & $7 \mathrm{~S} 2 \mathrm{R}^{\mathrm{a}}$ & $7 \mathrm{i}-3$ & 62 & 0.8 & Zielenski et al. (1991) \\
\hline 8 & I8D1 & I8R1 & 62 & 2.0 & Gasparini et al. (1991) \\
\hline 9 & $9 \mathrm{i}-5 \mathrm{~s}$ & 9ii-3 & 62 & 1.0 & Shackleton et al. (1994) \\
\hline 10 & $10 \mathrm{R}-5^{\mathrm{c}}$ & $10 \mathrm{~L}-3^{\mathrm{c}}$ & 60 & 0.8 & This study \\
\hline 11 & $11 \mathrm{i}-5$ & $11 \mathrm{ii}-3^{\mathrm{b}}$ & 62 & 0.8 & Zielenski et al. (1991) \\
\hline 12 & $12 \mathrm{R}-5^{\mathrm{c}}$ & $12 \mathrm{~L}-3^{\mathrm{c}}$ & 60 & 0.8 & This study \\
\hline \multirow[t]{3}{*}{13} & Ex13-5 & $13 \mathrm{~L} 1^{\mathrm{a}}$ & 62 & 0.8 & Shackleton et al. (1994) \\
\hline & $13 \mathrm{~F} 1-5^{\mathrm{c}}$ & $13 \mathrm{R} 1-3^{\mathrm{c}}$ & 62 & 0.8 & This study \\
\hline & & Ex13-3 & 62 & 0.8 & Shackleton et al. (1994) \\
\hline $14 \mathrm{a}$ & 14aii-5 & 14aii-3 & 62 & 1.0 & Fanen et al. (1992) \\
\hline $14 \mathrm{~b}$ & 14 bii- $5^{a}$ & $14 \mathrm{bii}-3$ & 62 & 0.8 & Shackleton et al. (1994) \\
\hline \multirow[t]{2}{*}{15} & $15 \mathrm{i}-5$ & $15 \mathrm{~S} 1 \mathrm{~L}^{\mathrm{a}}$ & 62 & 0.8 & Zielenski et al. (1991) \\
\hline & $15 \mathrm{~S} 1 \mathrm{R}^{\mathrm{a}}$ & $15 \mathrm{i}-3$ & 62 & 0.8 & Zielenski et al. (1991) \\
\hline 16 & $16 \mathrm{ii}-5$ & $16 \mathrm{ii}-3^{\mathrm{b}}$ & 62 & 0.8 & Shackleton et al. (1994) \\
\hline $17 \mathrm{a}$ & 17aii-5 & 17aii-3 & 57 & 1.0 & Fanen et al. (1992) \\
\hline \multirow[t]{2}{*}{$17 \mathrm{~b}$} & $17 \mathrm{bi}-5$ & $17 \mathrm{~b} 1 \mathrm{~L}^{\mathrm{a}}$ & 62 & 0.8 & Zielenski et al. (1991) \\
\hline & $17 \mathrm{~b} 1 \mathrm{R}^{\mathrm{a}}$ & $17 \mathrm{bi}-3$ & 62 & 0.8 & Zielenski et al. (1991) \\
\hline 18 & $18 \mathrm{R}-5^{\mathrm{c}}$ & $18 \mathrm{~L}-3^{\mathrm{c}}$ & 60 & 0.8 & This study \\
\hline \multirow[t]{2}{*}{19} & $19 \mathrm{i}-5$ & $E 2 L^{d}$ & 62 & 1.0 & Zielenski et al. (1991) \\
\hline & $\mathrm{F} 1 \mathrm{R}^{\mathrm{d}}$ & $19 \mathrm{i}-3$ & 62 & 1.0 & Zielenski et al. (1991) \\
\hline 20 & $20 \mathrm{ii}-5^{\mathrm{a}}$ & $20 \mathrm{ii}-3^{\mathrm{a}}$ & 64 & 0.8 & \\
\hline
\end{tabular}

a. Primer sequences were described elsewhere by A. Harris, Paediatric Molecular Genetics, Institute of Molecular Medicine, Oxford University, Oxford, UK.

b. Cabello et al. (2001).

c. Sequences of new primers are as follows $\left(5^{\prime} \rightarrow 3^{\prime}\right)$ : 10R-5', CAAGTGAATCCTGAGCGTGA; 10L-3', GTGTGAAGGGTTCATATGCA; 12R-5', GTGAATCGATGTGGTGACCA; 12L-3', TG CCATACCAACAATGGTGA; 13F1-5', gctcaaaactcatgggattgta; 13R1-3', tctcctgctcagaatctggta (lowercase letters denote sequences within exons); 18R-5', AGTCGTTCACAGAAGAGAGA; and 18L-3', ACAGATACACAGTGACCCTCA.

d. Primer sequence described by Chalkley and Harris (1991).

gous with DF508, and 2 in patients who presented this mutation as a heterozygous compound with another unknown mutation.

The $3120+1 \mathrm{G} \rightarrow \mathrm{A}$ mutation was found in one homozygous patient, in two patients who were heterozygous with DF508, and in three patients who were heterozygous with an unknown mutation, totaling 7 out of 190 (3.7\%) chromosomes. 
The R334W mutation was detected in 5 out of 190 (2.63\%) chromosomes (2 heterozygous DF508/R334W patients and 3 heterozygous R334W/non-DF508 patients); the G542X mutation was found in 4 out of $190(2.1 \%)$ chromosomes (3 compound heterozygous patients with DF508 and 1 compound heterozygous patient with unknown mutation). Finally, the P205S mutation was found in two compound heterozygous DF508/P205S patients (1.05\%).

These five mutations (G85E, 3120 + 1G $\rightarrow$ A, R334W, G542X, and P205S) account for $14.21 \%$ of the CF alleles. Five other mutations [G551D, R1162X, $\mathrm{Y} 1092 \mathrm{X}(\mathrm{C}>\mathrm{A}), \mathrm{S} 549 \mathrm{R}(\mathrm{T}>\mathrm{G})$, and S4X] were observed with a frequency less than $1 \%$ and accounted for only $2.63 \%$ of the alleles (Table 2 ).

As a result of this extensive screening study, we have accounted for $45.26 \%$ of the CF alleles in the Rio de Janeiro population and accomplished the complete genotyping in $34.7 \%$ of the patients (33/95). Twenty of the 95 patients were found to carry only one mutation, and for 42 patients $(44.2 \%)$ both mutations are still unknown.

During the course of this study, several known polymorphisms in the coding region of CFTR were detected (IVS6a, IVS8PoliT, $1540 \mathrm{~A} / \mathrm{G}, 2134 \mathrm{~T} / \mathrm{C}$, $2694 \mathrm{G} / \mathrm{T}, 3030 \mathrm{G} / \mathrm{A}, 3123 \mathrm{G} / \mathrm{C}, 3212 \mathrm{~T} / \mathrm{C}$, and $4002 \mathrm{~A} / \mathrm{G})$, some of which are reportedly functionally and phenotypically important (Cuppens et al. 1998; Rowntree and Harris 2003). Because we performed automated sequencing of the CF exons, some of these polymorphisms could be evidenced during the analysis of the data. The M470 (1540 A/G) and the T854 (2694 G/T) polymorphisms were observed in $59 \%$ and $79.5 \%$ of the chromosomes, respectively.

\section{Discussion}

$\mathrm{CF}$ mutations are already well defined for countries where the prevailing population is Caucasian. In some regions, important racial admixture has led to complex ethnicity, and therefore it is crucial to develop more accurate and less expensive molecular screening strategies for defining the frequent mutations in the CFTR gene of CF patients (Federici at al. 2001).

In this study we analyzed the whole coding CFTR region and intronic boundaries by SSCP analysis and DNA sequencing, revealing the presence of 11 different mutations in a sample of $95 \mathrm{CF}$ patients from Rio de Janeiro, Brazil. These mutations correspond to $45 \%$ of the disease alleles in the studied population. The most common CF mutation in Caucasians is DF508; in this study, however, it accounted for only $28.42 \%$ of CF alleles.

The frequency of the DF508 mutation found in this sample differed from the $47.0 \%$ and $48.7 \%$ that have been observed in other Brazilian regions (Raskin et al. 1993; Bernardino et al. 2000; Streit et al. 2003). These regional differences can be explained by the different contribution of ethnic groups and different proportion of racial admixture. The Brazilian population is mainly the result of three-way ethnic admixture (Europeans, Africans, and Amerindians), the 
Table 2. CFTR Mutations in 95 Brazilian (Rio de Janeiro, Southeastern Brazil) Cystic Fibrosis Patients

\begin{tabular}{|c|c|c|c|c|c|}
\hline Genotype & Observed Number & Expected Number & $x^{2}$ & Allele & Allele Frequency $\pm S E$ \\
\hline DF508/DF508 & 13 & 7.662 & 3.718 & DF508 & $0.284211 \pm 0.032722$ \\
\hline DF508/non-DF508 & 10 & 29.570 & $12.952^{\mathrm{b}}$ & G542X & $0.021053 \pm 0.010415$ \\
\hline DF508/G542X & 3 & 1.187 & 2.768 & G551D & $0.005263 \pm 0.005249$ \\
\hline G542X/non-DF508 & 1 & 2.291 & 0.727 & S549R & $0.005263 \pm 0.005249$ \\
\hline DF508/G551D & 1 & 0.270 & 1.976 & $\mathrm{R} 1162 \mathrm{X}$ & $0.005263 \pm 0.005249$ \\
\hline S549R/non-DF508 & 1 & 0.521 & 0.441 & Y1092X & $0.005263 \pm 0.005249$ \\
\hline DF508/R1162X & 1 & 0.270 & 1.976 & $\mathrm{~S} 4 \mathrm{X}$ & $0.005263 \pm 0.005249$ \\
\hline DF508/Y1092X & 1 & 0.270 & 1.976 & P205S & $0.010526 \pm 0.007404$ \\
\hline DF508/S4X & 1 & 0.270 & 1.976 & R334W & $0.026316 \pm 0.011613$ \\
\hline DF508/P205S & 2 & 0.594 & 3.333 & $3120+1 \mathrm{G} \rightarrow \mathrm{A}$ & $0.036842 \pm 0.013666$ \\
\hline DF508/R334W & 2 & 1.403 & 0.254 & G85E & $0.047368 \pm 0.015411$ \\
\hline R334W/non-DF508 & 3 & 2.707 & 0.032 & Non-DF508 & $0.547368 \pm 0.036111$ \\
\hline DF508/3120 $+1 G \rightarrow A$ & 2 & 1.997 & 0.000 & & \\
\hline $3120+1 \mathrm{G} \rightarrow \mathrm{A} /$ non-DF508 & 3 & 3.852 & 0.189 & & \\
\hline $3120+1 \mathrm{G} \rightarrow \mathrm{A} / 3120+1 \mathrm{G} \rightarrow \mathrm{A} 10.1305 .819^{\mathrm{a}}$ & 1 & 0.130 & $5.819^{\mathrm{a}}$ & & \\
\hline DF508/G85E & 5 & 2.536 & 2.394 & & \\
\hline G85E/non-DF508 & 2 & 4.894 & 1.711 & & \\
\hline G85E/G85E & 1 & 0.210 & 2.975 & & \\
\hline Non-DF508/non-DF508 & 42 & 28.529 & $6.361^{\mathrm{a}}$ & & \\
\hline Noncharacterized & 0 & 5.8 & 5.8 & & \\
\hline Total CF individuals & 95 & 95.0 & $63.22 ; \mathrm{df}=9$ & & \\
\hline
\end{tabular}

Non-DF508 = Unknown mutation.

a. $0.01<p \leqslant 0.05$.

b. $p<0.001$. 
proportions of which vary in the different regions. Although the Portuguese contribution prevails, new waves of immigration from other European countries, mostly Germany, Italy, and Spain, were responsible for ethnic differences among southern regions. The genetic proportion of Europeans, Africans, and Amerindians in Rio de Janeiro is different from that in southern Brazil (40\% European, 52\% African, and 8\% Amerindian; Lopez-Camelo et al. 1996). Probably, other European and sub-Saharan populations contributed to the genetic pool that is now evidenced in Rio de Janeiro.

It is worth emphasizing that the G85E mutation, which occurs worldwide (prevalence ranging from $0.2 \%$ to 2.6\%) (Bonizzato et al. 1995; Bobadilla et al. 2002; Messaoud et al. 1996; Bayleran et al. 1996), was found in our sample in $4.73 \%$ of the chromosomes. This same mutation has been reported previously in São Paulo, southeastern Brazil, with a frequency of $1.3 \%$ (Bernardino et al. 2000). The factors that contributed to the enhancement of this frequency are still unknown.

The $3120+1 \mathrm{G} \rightarrow \mathrm{A}$ mutation is the second most frequent mutation in African American CF individuals; it is present in $12.2 \%$ of $\mathrm{CF}$ patients from this ethnic group (Macek et al. 1997). It has also been described in other regions, such as sub-Saharan Africa (25\%) (Carles et al. 1996), Reunion Island (8\%) (Cartault et al. 1996), Saudi Arabia (El-Harith et al. 1997), Bahrain (3.8\%) (Eskandarani 2002), and Greece (0.6\%) (Tzetis et al. 1997). Continuous gene flow between Arab and African populations probably has persisted for many centuries, in association with trading and the spread of Islam. This may provide an explanation for the common ancestry of disease mutations in these ethnically different populations (Dörk et al. 1998). The $3120+1 \mathrm{G} \rightarrow$ A mutation is present in $3.7 \%$ of our CF chromosomes. The relatively high frequency of this mutation in Rio de Janeiro presumably emerged through ethnic admixture with subSaharan Africans. This mutation, traditionally recommended for screening in African descendants, should be included in any CF screening for Brazilian populations.

The R334W mutation was first identified in southern European populations at a frequency of approximately 1\% (Gasparini et al. 1991). In Rio de Janeiro, $\mathrm{R} 334 \mathrm{~W}$ was found in $2.6 \%$ of CF chromosomes. Bernardino et al. (2000) and Streit et al. (2003) also observed this mutation in Brazilian samples, with a frequency of $2.5 \%$ and $1.3 \%$, respectively.

Two other mutations, G542X and R1162X, are also common in southern European populations. G542X is the most common mutation in Mediterranean regions, prevailing in Spain (14.4\%). Because of the geographic proximity with northern Africa, G542X is present at a frequency of $8.9 \%$ in this region (Bobadilla et al. 2002). R1162X presents a frequency of $9.8 \%$ in Italy (Bonizatto et al. 1995). In the present study G542X was found in $2.1 \%$ of the CF chromosomes, confirming data obtained in a nearby Brazilian state (São Paulo). R1162X presented a low frequency $(0.53 \%)$ that is different from what was found in the São Paulo population (2.5\%) (Bernardino et al. 2000). 


\section{2 / CABELLO ET AL.}

Four other rare mutations were observed in this analysis: P205S (1.05\%), Y1092X (0.53\%), S549R (0.53\%), and S4X (0.53\%). P205S was first identified in Spanish individuals (Chillon et al. 1994) and was present in 2 out of the 95 studied patients. The Y1092X mutation is a rare mutation, first identified in the French Canadian population (Bozon et al. 1994) with a frequency of $1.3 \%$. S549R was first identified by Kerem et al. (1990) in a Jewish Moroccan patient, and the mutation has a prevalence of $6.0 \%$ in that group. The S549R mutation has also been observed in Saudi Arabia (Banjar et al. 1999) and in the United Arab Emirates (Frossard et al. 1998). S4X has been found solely in a Slovenian population (0.8\%) (Ravnik-Glavac et al. 1993). These mutations have never been described in Brazil before.

CF mutations are extremely variable among different Brazilian regions. The genetic profile of the Rio de Janeiro population (southeastern Brazil) is peculiar, expressing characteristics of the ethnic admixture. The frequency of the DF508 mutation (28.42\%) in Rio de Janeiro is significantly lower $\left(\chi^{2}=19.75\right.$, $P=0.000)$ than what is found in São Paulo or other southern Brazilian states (Bernardino et al. 2000).

The significant difference between observed (10) and expected (29.57) compound heterozygous DF508/non-DF508 patients (Table 2) might indicate that some severe unidentified mutations are present in this group. Considering this aspect, one could assume that the high morbidity of the DF508/non-DF508 compound heterozygous genotype could have led to premature death of CF patients, diminishing their presence in the studied sample. The unknown allele (non-DF508) was associated with the D-7-2-1-2 (XV2c-KM19-IVS6a-TUB9M470-T854) haplotype in $40 \%$ of these DF508/non-DF508 patients. This evidence is corroborated by analyses of six autopsy specimens from CF patients that revealed DF508/non-DF508 genotypes in four of them (66.7\%) (data not shown). More profound studies are necessary to appropriately define these mutations and to investigate the hypothesis of a higher morbidity among the DF508/non-DF508 compound heterozygous patients.

Acknowledgments We would like to thank all the CF families for their cooperation in these investigations and the medical staff of the Centro de Genética Médica of Instituto Fernandes Figueira. We particularly thank Ann Harris for providing many oligonucleotide sequences. We also thank Rafael Derré for his collaboration with autopsy specimen analysis. We are grateful to Tamara Gomes Kalil for language assistance. Financial support for this research was supplied by Conselho Nacional de Desenvolvimento Científico e Tecnológico (CNPq), Financiadora de Estudos e Projetos (FINEP), and Programa de Apoio à Pesquisa Estratégica em Saúde/Fundação Oswaldo Cruz (PAPES/FIOCRUZ).

Received 15 April 2004; revision received 17 June 2004. 


\section{Literature Cited}

Axton, R. A., and D. J. H. Brock. 1995. A single-tube multiplex system for the simultaneous detection of 10 common cystic fibrosis mutations. Hum. Mutat. 5:260-262.

Banjar, H., M. Kambouris, B. F. Meyer et al. 1999. Geographic distribution of cystic fibrosis transmembrane regulator gene mutations in Saudi Arabia. Ann. Trop. Pediatr. 19(1):69-73.

Bayleran, J. K., H. Yan, C. A. Hopper et al. 1996. Frequencies of cystic fibrosis mutations in Maine population: High proportion of unknown alleles in individuals of French-Canadian ancestry. Hum. Genet. 98:207-209.

Bernardino, A. L. F., A. Ferri, M. R. Passos-Bueno et al. 2000. Molecular analysis in Brazilian cystic fibrosis patients reveals five novel mutations. Genet. Test. 4(1):69-74.

Bobadilla, J. L., M. Macek Jr., J. P. Fine et al. 2002. Cystic fibrosis: A worldwide analysis of CFTR mutations-Correlation with incidence of data and application to screening. Hum. Mutat. 19(6):575-606.

Bonizzato, A., L. Bisceglia, C. Marigo et al. 1995. Analysis of the complete coding region of the CFTR gene in a cohort of CF patients from north-eastern Italy: Identification of $90 \%$ of the mutations. Hum. Genet. 95:397-402.

Bozon, D., J. Zielenski, F. Raninsland et al. 1994. Identification of four new mutations in the cystic fibrosis transmembrane conductance regulator gene: I148T, L1077P, Y1092X, 2183AA $\rightarrow$ G. Hum. Mutat. 3:330-332.

Cabello, G. M. K., P. H. Cabello, J. Llerena Jr. et al. 2001. The $3120+1 \mathrm{G} \rightarrow$ A splicing mutation in CFTR is common in Brazilian cystic fibrosis patients. Hum. Biol. 73:403-409.

Cabello, G. M. K., A. F. Moreira, D. Horovitz et al. 1999. Cystic fibrosis: Low frequency of DF508 mutation in 2 population samples from Rio de Janeiro, Brazil. Hum. Biol. 71(2):189-196.

Cabello, P. H., and H. Krieger. 1977. GENIOC: Sistema para análises de dados de genética. Technical Publication. Rio de Janeiro, Brazil: Instituto Oswaldo Cruz, FIOCRUZ.

Carles, S., M. Desgeorges, A. Goldman et al. 1996. First report of CFTR mutations in black cystic fibrosis patients of southern African origin. J. Med. Genet. 33:802-804.

Cartault, F., J. Steffann, D. Vidaud et al. 1996. Detection of more then $91 \%$ cystic fibrosis mutations in a sample of the population from Reunion Island and identification of two novel mutations (A309G, S1255L) and one novel polymorphism (L49L). Clin. Genet. 54:437-439.

Chalkley, G., and A. Harris. 1991. Lymphocyte mRNA as a resource for detection of mutations and polymorphisms in CF gene. J. Med. Genet. 28(11):777-780.

Chillon, M., T. Casals, J. Giménez et al. 1994. Analysis of the CFTR gene confirms the high genetic heterogeneity of the Spanish population: 43 mutations account for only $78 \%$ of CF chromosomes. Hum. Genet. 93:447-451.

Cuppens, H., W. Lin, M. Jaspers et al. 1998. Polyvariant mutant cystic fibrosis transmembrane conductance regulator genes: The polymorphic $(\mathrm{Tg}) \mathrm{m}$ locus explains the partial penetrance of $\mathrm{T} 5$ polymorphism as disease mutation. J. Clin. Invest. 101:487-496.

Cystic Fibrosis Genetic Analysis Consortium (CFGAC). 2004. Available at http://www.genet.sickkids .on.ca/cftr/

Dörk, T., E. A. El-Harith, M. Stuhrmann et al. 1998. Evidence for a common ethnic origin of cystic fibrosis mutation $3120+1 \mathrm{G} \rightarrow \mathrm{A}$ in diverse populations. Am. J. Hum. Genet. 63:656-662.

El-Harith, E. A., T. Dörk, M. Stuhrmann et al. 1997. Novel and characteristic CFTR mutations in Saudi Arab children with severe cystic fibrosis. J. Med. Genet. 34:996-999.

Eskandarani, H. A. 2002. Cystic fibrosis transmembrane regulator gene mutations in Bahrain. J. Trop. Pediatr. 48(6):348-350.

European Working Group on Cystic Fibrosis Genetics. 1990. Gradient of distribution in Europe of the major CF mutation and of its associated haplotype. Hum. Genet. 85:436-445. 


\section{4 / CABELLO ET AL.}

Fanen, P., N. Ghanem, M. Vidaud et al. 1992. Molecular characterization of cystic fibrosis: 16 novel mutations identified by analysis of the whole cystic fibrosis transmembrane conductance regulator (CFTR) coding regions and splicing site junctions. Genomics 13:770-776.

Federici, S., A. Iron, M. P. Reboul et al. 2001. CFTR gene analysis in 207 patients with cystic fibrosis in southwest France: High frequency of N1303K and $1811+1.6 \mathrm{bA} \rightarrow \mathrm{G}$ mutations. Arch. Pediatr. 8(2):150-157.

Frossard, P. M., E. Girodon, K. P. Dawson et al. 1998. Identification of cystic fibrosis mutations in the United Arab Emirates: Mutations in Brief No. 133. Hum. Mutat. 11(5):412-413.

Gasparini, P., A. Bonizzato, M. Dognini et al. 1992. Restriction site generating polymerase chain reaction (RG-PCR) for the probeless detection of hidden genetic variation: Application to the study of some common CF mutations. Mol. Cell Probes 6:1-7.

Gasparini, P., V. Nunes, A. Savoia et al. 1991. The search for south European cystic fibrosis mutations: Identification of two new mutations, four variants, and intronic sequences. Genomics 10:193-200.

Kerem, B., J. M. Rommens, J. A. Buchanan et al. 1989. Identification of the cystic fibrosis gene: Genetic analysis. Science 245:1,073-1,080.

Kerem, B., J. Zielinski, D. Markiewicz et al. 1990. Identification of mutations in regions corresponding to the two putative nucleotide (ATP)-binding folds of the cystic fibrosis gene. Proc. Natl. Acad. Sci. USA 87:8,447-8,451.

Lopez-Camelo, J. S., P. H. Cabello, and M. G. Dutra. 1996. A simple model for the estimation of congenital malformation frequency in racially mixed populations. Braz. J. Genet. 19(4):659663.

Macek, M., Jr., A. Macková, A. Hamosh et al. 1997. Identification of common cystic fibrosis mutations in African Americans with cystic fibrosis increases the detection rate to $75 \%$. Am. J. Hum. Genet. 60:1,122-1,127.

Messaoud, T., C. Verlingue, E. Denamur et al. 1996. Distribution of CFTR mutations in cystic fibrosis patients of Tunisian origin: Identification of two novel mutations. Eur. J. Hum. Genet. 4:20-24.

Miller, A. S., D. D. Dykes, and H. F. Polesky. 1988. A simple salting-out procedure for extracting DNA from human nucleated cells. Nucleic Acids Res. 16(3):1,215.

Padoa, C., A. Goldman, and T. Jenkins. 1999. Cystic fibrosis carrier frequencies in populations of African origin. J. Med. Genet. 36:41-44.

Raskin, S., J. A. Phillips III, M. R. S. Krishnamani et al. 1993. DNA analysis of cystic fibrosis in Brazil by direct PCR amplification from Guthrie cards. Am. J. Med. Genet. 46:665-669.

Ravnik-Glavac, M., D. Glavac, R. Komel et al. 1993. Single-stranded conformation polymorphism analysis of the CFTR gene in Slovenia cystic fibrosis patients: Detection of mutations and sequence variations. Hum. Mutat. 2:286-292.

Rommens, J. M., B.-S. Kerem, and W. Greer. 1990. Rapid nonradioactive detection of the major cystic fibrosis mutation. Am. J. Hum. Genet. 46:395-396.

Rowntree, R. K., and A. Harris. 2003. The phenotypic consequences of CFTR mutations. Ann. Hum. Genet. 67:471-485.

Schwartz, M., H. K. Johansen, C. Koch et al. 1990. Frequency of the $\Delta$ F508 mutation on the CF chromosomes in Denmark. Hum. Genet. 85:427-428.

Shackleton, S., J. Hull, S. Dear et al. 1994. Identification of rare and novel mutations in the CFTR genes of CF patients in southern England. Hum. Mutat. 3:141-151.

Streit, C., A. C. Burlamaque-Neto, F. Abreu e Silva et al. 2003. CFTR gene: Molecular analysis in patients from south Brazil. Mol. Genet. Metab. 78:259-264.

Tsui, L.-C. 1992. Mutations and sequence variations detected in the cystic fibrosis transmembrane regulator (CFTR) gene: A report of the cystic fibrosis analysis consortium. Hum. Mutat. 1:197-203.

Tzetis, M., E. Kanavakis, T. Antoniadi et al. 1997. Characterization of more than $85 \%$ of cystic fibrosis alleles in the Greek population, including five novel mutations. Hum. Genet. 99:121125 . 
Vidaud, M., P. Fanen, J. Martin et al. 1990. Three point mutations in the CFTR gene in French cystic fibrosis patients: Identification by denaturing gradient gel electrophoresis. Hum. Genet. 85:446-449.

Zielenski, J., R. Rozmahel, D. Bozon et al. 1991. Genomic DNA sequence of the cystic fibrosis transmembrane conductance regulator (CFTR) gene. Genomics 10:214-228. 